\title{
EXPANSÃO DO ENSINO SUPERIOR E FORMAÇÃO PROFISSIONAL EM EDUCAÇÃO FÍSICA: UM MAPEAMENTO DOS CURSOS NA MODALIDADE DE EDUCAÇÃO A DISTÂNCIA
}

\author{
Fernanda Cruvinel Pimentel
}

Universidade de Brasília, Brasília, Distrito Federal, Brasil

Ari Lazzarotti Filho

Universidade Federal de Goiás, Goiânia, Goiás, Brasil

Humberto Luís de Deus Inácio

Universidade Federal de Goiás, Goiânia, Goiás, Brasil

Edson Marcelo Húngaro

Universidade de Brasília, Brasília, Distrito Federal, Brasil

Fernando Mascarenhas

Universidade de Brasília, Brasília, Distrito Federal, Brasil

\section{Resumo}

Este artigo apresenta um estudo exploratório que propõe um mapeamento da oferta de cursos de Educação Física através da Educação a Distância, buscando identificar as tendências e nuances desta modalidade de formação como estratégia de expansão do ensino superior. Como resultados foram mapeados (28) cursos de Educação Física a distância, sendo (24) por Instituições públicas e gratuitas através do Sistema UAB e (4) por outras Instituições. A quantidade de vagas disponibilizadas por estas outras Instituições chega a quase $50 \%$ do total das matrículas. Compreendemos que há necessidade de estudos aprofundados sobre o processo de ensino e aprendizagem nesta modalidade, o que demanda a incorporação do tema da formação profissional a distância na agenda de pesquisa da área.

Palavras-chave: Educação Física e Treinamento. Educação a Distância. Política de Educação Superior.

\section{Introdução}

s mudanças na realidade macroeconômica e sociopolítica, bem
como as orientações internacionais para as políticas educacionais no país a partir da década de 1990, impactaram também as formas de organização do ensino superior. No período pós a Lei de Diretrizes e Bases da Educação Nacional (BRASIL, 1996), há um forte crescimento do número de instituições e cursos por meio da iniciativa privada, com o aumento da concorrência no setor, estimulando a busca de novas alternativas e modalidades de educação. 
Assim, a expansão do ensino superior no Brasil passa a se caracterizar pela flexibilização e diversificação. Os currículos foram enxugados, novos cursos foram criados - mais breves, baratos e alinhados com as demandas imediatas - e novas modalidades começaram a ser experimentadas, em especial, por meio da modalidade a distância (GIOLO, 2010).

A formação profissional vem, pouco a pouco, assumindo outras feições, conforme avançavam as transformações do mundo do trabalho. Seguindo a lógica capitalista, os modelos tradicionais de educação cedem espaço a outros que atendam mais rapidamente as novas exigências do mercado. Neste contexto, com o desenvolvimento das novas tecnologias de informação e comunicação, principalmente com a educação em rede, a modalidade de educação à distância (EaD) impulsionou a oferta de novos cursos de ensino superior, passando a se constituir como uma referência para as políticas de expansão, em especial, aquelas voltadas à formação de professores (DOURADO, 2008).

Como reação ao avanço do setor privado na oferta de cursos por meio da $\mathrm{EaD}$, é somente no início dos anos 2000 que, sob o discurso da expansão, interiorização e democratização, estabelece-se a base legal que confere sustentação à modalidade e são lançados os primeiros programas governamentais voltados à $\mathrm{EaD}$.

Tendo como objetivo oferecer formação inicial a distância a professores em exercício do ensino fundamental ou médio dos sistemas públicos, foram criados o Programa Pró-Licenciatura (Prolicen), em 2004, e o Sistema Universidade Aberta do Brasil (UAB), em 2005, com fins de consolidação de uma política pública de formação de professores e expansão do ensino superior por meio da modalidade a distância ${ }^{1}$.

Tal política está orientada para a democratização do acesso e se justifica pela necessidade de formação dos profissionais da educação

1- O sistema UAB foi construído pelo Ministério da Educação (MEC) e pela Associação dos Dirigentes das Instituições Federais de Ensino (Andifes) no âmbito do Fórum das Estatais pela Educação. Tanto a UAB como o Pró-Licenciatura estruturam-se a partir de parcerias com as universidades públicas, por meio de consórcios com municípios e estados da Federação. Os cursos oferecidos através do sistema UAB são lançados a partir de editais. O Sistema já lançou os editais UABI em 2005, UAB II em 2006, o Programa Nacional de Formação de Professores da Educação Básica (PARFOR) em 2009 e UABIII em 2011. O programa Pró-Licenciatura também criado em 2005 foi incorporado ao Sistema UAB. 
como fator de melhoria da qualidade da educação básica.

Mas o que dizer da qualidade desta formação? Belloni (2002) e Selwyn (2008) defendem positivamente a modalidade a distância, no sentido de compreender que com o avanço das tecnologias e sua respectiva inserção no meio educacional, novas possibilidades de ensino e aprendizagem devem ser experimentadas. Acreditam que a EaD é capaz de estabelecer relações sociais e interativas que encaminhem o aluno a um sistema crítico e interdisciplinar de educação.

Contudo, Barreto (2008), Giolo (2008) e Sousa (2007) defendem que as novas tecnologias, conjugadas com o fim das relações diretas e intersubjetivas da sala de aula e a implantação de novas formas de organização do trabalho pedagógico - os pacotes de ensino, os tutores, a separação da prática e da pesquisa etc. - fazem com que esta modalidade de ensino precarize o ensino superior, barateando a formação e esvaziando o trabalho docente.

Há, portanto, uma grande controvérsia em torno da expansão do ensino superior através da modalidade $\mathrm{EaD}$. Todavia, em função dos limites deste trabalho, não foi nossa intenção engajar-se neste debate, embora cientes de sua importância. A proposta é reunir subsídios e fomentar a discussão para localizar a Educação Física (EF) neste cenário. Neste sentido, nosso objetivo consiste em mapear a oferta de cursos de $\mathrm{EF}$ através da $\mathrm{EaD}$, buscando identificar as tendências e nuances desta política e modalidade de formação.

\section{Delineamento do estudo}

Esta investigação constituiu-se em um estudo exploratório de caráter quanti-qualitativo, o que envolveu o mapeamento dos cursos de EF oferecidos na modalidade a distância no país e a análise e discussão sobre as políticas de expansão do ensino superior por meio da $\mathrm{EaD}$, com seus desdobramentos para área. Sob o ponto de vista operacional e técnico, o caminho metodológico percorrido foi delineado a partir da análise documental.

Identificamos nesta técnica a possibilidade de reunir um grande número de informações e, a partir de documentos específicos, extrair dados essenciais acerca da abrangência dos cursos de EF na modalidade a distância, a saber: número de instituições; número de cursos superiores em EF; número de matrículas por grau acadêmico e modalidade; número de vagas; concluintes; matrículas por IES na moda- 
lidade a distância; número de cursos de licenciaturas a distância; comparação com outros cursos; quantidade de polos; distribuição por região; ano de início do curso; carga horária; avaliação. As principais fontes ou base de dados utilizados foram os portais: Sistema e-MEC (MEC, 2013), Universidade Aberta do Brasil (UAB, 2012), Censo da Educação Superior (Censup) (INEP, 2011) e Instituições de Ensino Superior (IES).

\section{Apresentação e análise dos dados}

Dentre os 1.058 cursos de EF oferecidos no país, 663 cursos são de licenciatura e 395 de bacharelado. O cenário mais geral correspondente à oferta de cursos de EF no país pode ser observado a partir da Tabela 1, na qual se apresentam o número de cursos e de matrículas em Licenciatura e Bacharelado, e as respectivas ofertas nos setores público e privado, bem como o percentual do total equivalente a cada um destes dados.

Tabela 1: Dados Gerais dos cursos de EF presenciais e a distância

\begin{tabular}{cccccccc}
\hline & $\begin{array}{c}\text { Licenciatur } \\
\mathrm{a}\end{array}$ & $\begin{array}{c}\text { Públic } \\
\mathrm{o}\end{array}$ & $\begin{array}{c}\text { Privad } \\
\mathrm{o}\end{array}$ & $\begin{array}{c}\text { Bacharelad } \\
\mathrm{o}\end{array}$ & $\begin{array}{c}\text { Públic } \\
\mathrm{o}\end{array}$ & Privado & Total \\
\hline Cursos $\left(\mathrm{n}^{\circ}\right)$ & 663 & 205 & 458 & 395 & 88 & 307 & 1.058 \\
\hline Cursos $\%$ ) & 62,67 & 30,92 & 69,08 & 37,33 & 22,28 & 77,72 & - \\
$\begin{array}{c}\text { Matrículas }\left(\mathrm{n}^{\circ}\right. \\
\text { ) }\end{array}$ & 123.269 & & 88.532 & 58.137 & & 46.132 & 181.40 \\
$\begin{array}{c}\text { Matrícula } \\
(\%)\end{array}$ & 67,95 & 28,17 & 71,83 & 32,05 & 20,65 & 79,35 & - \\
\hline
\end{tabular}

Fonte: (INEP/MEC, 2011).

As políticas para expandir a educação superior, a partir da criação do Prolicen e da UAB, fizeram surgir os primeiros cursos de EF a distância, vinculados a IES públicas. De acordo com o Censo da Educação Superior 2011, atualmente são 28 cursos, sendo todos de licenciatura, oferecidos na modalidade a distância. No total são 24 oferecidos por IES públicas e gratuitas que ofertam cursos através do Sistema UAB e 4 por outras IES não gratuitas, sendo uma comunitária pública não-estatal, uma municipal e duas privadas. Tais números sugerem que, ao contrário do ensino presencial, com forte presença do setor privado, na modalidade a distância, há uma predominância do setor público. Todavia, ao se observar o número de matrículas (Tabela 2), tal predominância deve ser relativizada, conforme se vê na Tabela 3 . 
Tabela 2: Dados Gerais das matrículas nos cursos a distância

\begin{tabular}{cccc}
\hline Matrículas & Geral & EF & $\begin{array}{c}\text { \% de matrículas da } \\
\text { EF }\end{array}$ \\
\hline Total & 6.739 .689 & 181.406 & 2,69 \\
Presencial & 5.746 .762 & 176.430 & 3,07 \\
Distância & 992.927 & 4.976 & 0,50 \\
\hline
\end{tabular}

Fonte: (INEP/MEC, 2011)

Tabela 3: Dados Gerais dos cursos de EF a distância

\begin{tabular}{cccc}
\hline & Licenciatura & Sistema UAB & Outras \\
\hline Cursos $\left(\mathrm{n}^{\circ}\right)$ & 28 & 24 & 4 \\
Cursos $(\%)$ & $100 \%$ & $85,71 \%$ & $14,29 \%$ \\
Matrículas $\left(\mathrm{n}^{\circ}\right)$ & 4.976 & 2.696 & 2.280 \\
Matrículas $(\%)$ & - & $54,18 \%$ & $45,82 \%$ \\
\hline
\end{tabular}

Fonte: (INEP/MEC, 2011)

De modo geral, o número de matrículas na modalidade a distância é bastante expressivo. Enquanto a modalidade presencial soma 5.746.762 matrículas, $85,27 \%$ do total, a modalidade a distância tem 992.927 matrículas, representando $14,73 \%$ do total das 6.739 .689 matrículas. No caso específico da EF, a modalidade presencial soma 176.430 matrículas, $97,25 \%$ do total da área, enquanto a modalidade a distância tem 4.976 matrículas, representando somente $2,74 \%$ do total das 181.406 matrículas. A EF tem uma participação de 3,07\% no total de alunos matriculados na modalidade presencial. Já na modalidade a distância esta participação decresce para $0,50 \%$. Chama atenção, no entanto, que apesar das IES públicas e gratuitas que ofertam cursos através do Sistema UAB serem responsáveis por $82,7 \%$ dos cursos de $\mathrm{EF}$ ofertados por meio da $\mathrm{EaD}$, elas detêm apenas $54,18 \%$ das matrículas, pois os outros $45,82 \%$ correspondem à parcela de alunos matriculados em cursos das outras Instituições que ofertam cursos não gratuitos.

Em relação aos 28 cursos de EF na modalidade a distância, 27 são ofertados por universidades, sendo 24 vinculadas ao Sistema UAB, e 1 curso ofertado por um centro universitário. Este mesmo centro universitário é responsável também pela oferta do único curso de bacharelado em EF na modalidade a distância ${ }^{2}$. A forte presença do setor

2- O curso de Bacharelado foi criado pelo Centro Universitário Claretiano (CEUCLAR) em 2012, de acordo com dados do Portal do e-MEC (2013). e por isso não consta no Censo da Educação Superior (INEP, 2011).

Pensar a Prática, Goiânia, v. 16, n. 4, p. 956-1270, out./dez. 2013 
público na oferta de cursos de EF na modalidade a distância vem sendo impulsionada pela UAB, cujos objetivos estão voltados para a democratização do acesso ao ensino superior e para a expansão dos cursos de licenciatura, buscando reduzir o déficit de professores com formação específica na educação básica em regiões mais afastadas dos grandes centros. Não por acaso, todos os cursos de EF oferecidos através do sistema UAB são de licenciatura.

Com 28 cursos de licenciatura, a EF ocupa a quinta posição na oferta de cursos de licenciatura na modalidade a distância, atrás da Pedagogia com 117 cursos, a Matemática com 64, a Biologia com 54 e a Química com 34. Apesar disto, esta ordem não é a mesma quando é observado o número de matrículas por curso: os cinco cursos na modalidade a distância com maior número de alunos são: pedagogia (281.541 mil matrículas); administração (140.210 mil matrículas); serviço social (80.650 mil matrículas) - curso com a maior relação de matrículas por curso; empreendedorismo (53.546 mil matrículas); e gestão de pessoal e recursos humanos (47.310 mil matrículas) 3 .

Os 4.976 alunos do curso de EF a Distância distribuem-se por 12 IES - sendo 8 IES vinculadas ao Sistema UAB e 4 outras IES. Todas oferecem os cursos por meio de polos. As IES vinculadas ao Sistema UAB são: Universidade de Brasília (UnB), Universidade Federal do Amazonas (UFAM), Universidade Estadual da Bahia (UNEB), Universidade Federal do Rio Grande do Norte (UFRN), Universidade Federal do Espírito Santo (UFES), Universidade Federal de Goiás (UFG), Universidade Estadual de Ponta Grossa (UEPG) e Universidade Federal do Amapá (UNIFAP). Já as outras IES: Universidade Regional do Nororeste do Estado do Rio Grande do Sul (UNIJUÍ) 4 , Universidade de Taubaté (UNITAU) ${ }^{5}$, Universidade Fumec (FUMEC) e Centro Universitário Claretiano (CEUCLAR) ${ }^{6}$.

Enquanto as universidades em geral são responsáveis por 3.090 matrículas, o curso de licenciatura ofertado pelo centro universitário, sozinho, é responsável por 1.886 matrículas, isto sem contabilizar

\footnotetext{
3- Nesse sentido, esses dados nos mostram que existem cursos que merecem ainda mais atenção na relação entre número de cursos e matrículas, principalmente os cursos de Serviço Social e Pedagogia, que estabelecem uma média de 5.760 e 2.406 matrículas por curso, respectivamente.

4-Instituição pública não estatal - paga.

5-Instituição pública municipal - paga.

6-FUMEC e CEUCLAR, instituições privadas.
}

Pensar a Prática, Goiânia, v. 16, n. 4, p. 956-1270, out./dez. 2013 
mais 900 vagas de seu curso de bacharelado abertas em 2012 que certamente se converteu em novas matrículas (MEC, 2013).

Os cursos do Sistema UAB vêm sendo ofertados por cinco editais: Pró-Licenciatura (2007/2008), UABI(2007), UABII(2009), PARFOR(2009)7 , UABIII(2011) e UABIV(2013). Assim sendo, apesar do Censo da Educação Superior 2011 (INEP, 2011) indicar a existência de 24 cursos através das IES vinculadas ao Sistema UAB, conseguimos identificar através do Portal do e-MEC (E-MEC, 2013) e do Portal da UAB (UAB, 2013) apenas 12 ofertas até 2012. Confira a tabela 4.

Tabela 4: Oferta de cursos de EF a Distância através do Sistema UAB

\begin{tabular}{cccccc}
\hline IES & Edital & $\begin{array}{c}\text { Número de } \\
\text { vagas }\end{array}$ & Currículo & $\begin{array}{c}\text { Quantidade } \\
\text { de Polos }\end{array}$ & Região \\
\hline UNB & $\begin{array}{c}\text { Pró-Licenciatura; } \\
\text { UABI; UABII; } \\
\text { UABII; }\end{array}$ & 600 a 800 & 8 semestres & 6 a 10 & $\begin{array}{c}\text { Centro- } \\
\text { Oeste }\end{array}$ \\
UFG & UAB II; PARFOR & 400 a 600 & 8 semestres & 6 a 10 & $\begin{array}{c}\text { Centro- } \\
\text { Oeste }\end{array}$ \\
UFRN & PARFOR & 400 a 600 & 8 semestres & 6 a 10 & Nordeste \\
\hline UNEB & PARFOR & 150 a 200 & 8 semestres & 6 a 10 & Nordeste \\
UNIFAP & PARFOR & $<100$ & 8 semestres & 1 a 5 & Norte \\
UFAM & PARFOR & - & 10 semestres & 1 a 5 & Norte \\
\hline UEPG & UAB II & 100 a 150 & 8 semestres & 1 a 5 & Sul \\
UFES & Pró-Licenciatura & 600 a 800 & 10 semestres & 6 a 10 & Sudeste \\
\hline
\end{tabular}

Fonte: e-MEC; Portal da UAB; PPP dos cursos de EF a Distância (Janeiro, 2013).

A Universidade de Brasília (UNB) é pioneira na formação de professores de EF a Distância através do Sistema UAB. A Universidade participou de quatro, dos cinco editais de oferta: Pró-Licenciatura, UABI, UABII, e UABIII. O Pró-Licenciatura foi o primeiro edital a ser aprovado, porém a UABI iniciou no primeiro semestre de 2007/1 e o Pró-Licenciatura iniciou no segundo semestre 2007/2. A UABII iniciou em 2009/1 e a UABIII em 2011/1. A instituição oferece esses cursos em sete polos espalhados por três regiões do Brasil, sendo que teve polo que chegou a receber até três ofertas de cursos. A carga horária é de 2.910 horas a serem cumpridas em oito semestres, no míni-

7- Edital específico para a formação de professores leigos em exercício. A dinâmica do processo didático pedagógico deste edital é o mesmo que recebem os outros editais da UAB. Apenas o critério de acesso a este curso que é diferente, pois não é através de vestibular e sim com a comprovação de estar atuando na educação básica sem formação específica. 
mo. A UnB é responsável pela formação da primeira turma de professores de EF através do Sistema UAB.

A Universidade Federal do Amazonas (UFAM) oferece o curso de licenciatura em EF pelo Programa de Formação de Professores da Educação Básica - PARFOR vinculado ao Sistema UAB. O curso é oferecido em cinco polos do estado do Amazonas. A carga horária do curso deve ser cumprida no mínimo, em dez semestres. Não foram encontradas informações referente a quantidade vagas oferecidas, matrículas efetuadas, e ano de início.

A Universidade Estadual da Bahia (UNEB) oferece o curso de licenciatura em EF através do PARFOR. O curso é ofertado em seis polos do estado da Bahia, sendo 35 vagas em cada polo. O curso teve início no ano de 2011 e o ingresso não se deu por vestibular, mas sim por inscrição na plataforma freire para atender público específico. Não há informações sobre a carga horária

A Universidade Federal do Rio Grande do Norte (UFRN) oferece o curso de licenciatura em EF em dez polos, todos situados no estado do Rio Grande do Norte. Foram oferecidas 520 vagas, 60 vagas em dois polos, 50 vagas em oito polos, e efetivadas 511 matrículas. O curso é oferecido pelo edital da UABIII e teve início em 2012/2. A carga horária é de 2.835 horas que deverão ser cumpridas no prazo mínimo de oito semestres. $\mathrm{O}$ ingresso neste curso aconteceu de duas maneiras: Através do PARFOR (para professores que já são da rede de ensino, mas leigos) e outra via vestibular ${ }^{8}$. A priori foram destinadas 30 vagas para o PARFOR e o restante destinado ao vestibular. A concorrência variou entre 5 e 19 candidatos por vaga, respectivamente.

A Universidade Federal do Espírito Santo (UFES) oferece o curso de licenciatura em EF através do Programa Pró-Licenciatura integrada ao Sistema UAB em dez polos do estado do Espírito Santo. Foram ofertadas 754 vagas, e efetivadas no primeiro semestre 507 matriculas. A carga horária do curso é de 3.125 horas a serem cumpridas no mínimo de dez semestres (cinco anos). O curso teve início em novembro de 2008, mas como o primeiro semestre era mais extenso, contou como sendo o primeiro semestre 2009/1. O processo de seleção foi por meio de processo seletivo/vestibular e o ingresso no curso se deu por ordem de classificação, tendo como referência, ser professor em exer-

8- No Portal do e-MEC (MEC. 2013) não consta o ano de início do curso. Portanto, algumas informações foram conseguidas através do coordenador do curso de licenciatura em Educação Física da UFRN. 
cício atuando da $5^{\text {a }}$ serie do ensino fundamental ao ensino médio, ter o ensino médio completo e ter sido classificado em processo isolado de seleção ${ }^{9}$.

A Universidade Federal de Goiás (UFG) conta com dois cursos de licenciatura vinculados a UAB. O curso através do edital da UABII iniciou em outubro de 2009/2 em nove polos de apoio presencial, todos no estado de Goiás. A entrada no curso foi por meio de processo seletivo/vestibular, com demanda aberta. Foram ofertadas 315 vagas, sendo 35 em cada polo (UFG, 2013). O outro curso de licenciatura em EF na modalidade a distância da UFG é ofertado a partir do PARFOR com início em 2010/1. Neste curso, 215 estudantes foram selecionados dentre os cinco polos do estado de Goiás. A carga horária de ambos os cursos deve ser cumprida, no mínimo, em oito semestres.

A Universidade Estadual de Ponta Grossa (UEPG) oferece o curso de licenciatura em EF em cinco polos do estado do Paraná através do edital da UABII. O curso teve início no ano de 2009/1 e ofertou 150 vagas, sendo 30 vagas para cada polo de apoio presencial. A carga horária do curso deve ser cumprida no mínimo de oito semestres.

A Universidade Federal do Estado do Amapá (UNIFAP) oferece o curso de licenciatura em EF no polo de Macapá-AP, com carga horária a ser cumprida no mínimo em oito semestres. O curso ofertou 50 vagas para ingresso neste polo através do edital do PARFOR, porém não foram encontradas informações referentes ao número de matrículas e nem ao ano de início.

Voltando a dissertar sobre os cursos desde uma perspectiva mais geral, o Censo da Educação Superior (INEP, 2011), indica que 194 sujeitos já concluíram o curso de licenciatura em EF na modalidade a distância. Sendo que, 81 concluíram o curso através de IES vinculada ao Sistema UAB, e 113 através de outras IES.

Em relação ao total de polos dos cursos de EF a Distância do Brasil, o quadro mostra que apesar das instituições vinculadas ao Sistema UAB deterem $82,7 \%$ dos cursos ofertados, as outras IES detêm $48,2 \%$ dos polos. De acordo com dados do Portal do e-MEC (2013), os cursos de EF são oferecidos em 134 polos distribuídos por todas as cinco regiões do território brasileiro. Deste total, 69 polos de IES vinculadas ao Sistema UAB, e 67 polos das outras IES. É importante ressaltar que, desta quantidade de polos das outras IES, 64 polos são de res-

9- Informações conseguidas com a coordenadora do Programa Pró-Licenciatura de Educação Física da UFES. 
ponsabilidade dos cursos de Licenciatura e Bacharelado oferecidos pelo Centro Universitário Claretiano (CEUCLAR). Esse dado indica uma forte concentração da oferta nas mãos de uma única instituição privada.

No que tange à distribuição geográfica dos polos, a distribuição do curso se concentra hegemonicamente na Região Sudeste, onde foram identificados 49 polos de oferta do curso de EF. Porém, as Regiões Nordeste e Centro-Oeste aparecem com 28 e 26 polos de oferta, respectivamente, o que representa uma quantidade significativa de polos em Regiões menos desenvolvidas economicamente. Esse percentual indica o esforço de interiorização e inclusão de professores no Ensino Superior, porém ainda não atinge toda a população do Brasil.

Quatro estados da região Norte (Pará, Acre, Roraima e Rondônia), cinco estados do Nordeste (Maranhão, Piauí, Ceará, Sergipe e Pernambuco), um estado do Sudeste (Rio de Janeiro), dois estados do Centro-Oeste (Mato Grosso e Mato Grosso do Sul), e dois estados da região Sul (Santa Catarina e Rio Grande do Sul) não possuem polos de IES vinculadas ao Sistema UAB que oferecem o curso de licenciatura em EF a Distância.

Outros aspectos merecem destaque em relação à distribuição de polos do curso de EF entre as IES:

a. Entre as quatro outras IES que oferecem o curso no Brasil:

- Três oferecem o curso em apenas um polo de um único estado em uma grande cidade. Dois destes na Região Sudeste e um na Região Sul. Dois cursos oferecem 100 vagas e um curso oferece 240 vagas no único polo de oferta.

- Uma instituição é responsável por 34 polos distribuídos por 15 estados no curso de licenciatura e 30 polos distribuídos por 14 estados no curso de bacharelado presentes nas cinco regiões brasileiras. $\mathrm{O}$ curso de licenciatura ofereceu 2.000 vagas e o curso de Bacharelado 900 vagas.

b. Entre as oito IES vinculadas ao Sistema UAB que oferecem o curso no Brasil:

- Sete instituições têm todos os polos no estado de origem.

- Uma instituição têm polos distribuídos em sete estados.

No que se refere a avaliação dos cursos e infraestrutura da sede e dos polos, os cursos superiores na modalidade a distância passam pelos mesmos processos e trâmites legais definidos pelo MEC para o funcionamento de cursos superiores, embora com categorias e indicadores específicos a modalidade.

Pensar a Prática, Goiânia, v. 16, n. 4, p. 956-1270, out./dez. 2013

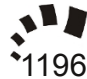


Entre as oito IES vinculadas ao Sistema UAB em atividade, nenhuma ainda havia sido submetida à avaliação. No entanto, apesar de ainda não constar na base de dados do Portal do e-MEC (E-MEC, 2013), o curso de licenciatura em EF a distância da Universidade de Brasília (UNB) foi avaliado no ENADE com nota 4, no ano de 2012.

Entre as outras IES, três cursos de licenciatura já foram avaliados no ENADE com nota 4 e um destes cursos já obteve o Conceito Preliminar do Curso (CPC) ${ }^{10}$ também com nota 4 . Mas nenhum curso, incluindo da rede pública ou privada, já teve o Conceito do Curso (CC) permanente instituído de acordo com a base de dados do e-MEC (EMEC, 2013).

A iniciativa de organização de um processo de avaliação de cursos e IES, data desde a década de 1980 com a existência de algumas avaliações isoladas, evoluindo com a consolidação e implementação de algumas políticas, até chegar no atual modelo de avaliação desenvolvido a partir da implantação do Sistema Nacional de Avaliação da Educação Superior (SINAES). É importante ter um olhar cuidadoso com a avaliação, pois esta é considerada o ponto frágil nos cursos da modalidade a distância.

\section{Considerações finais}

Este artigo propôs mapear a oferta de cursos de EF através da $\mathrm{EaD}$, buscando identificar as tendências e nuances desta política e modalidade de formação. Os resultados indicam a necessidade de um olhar cuidadoso e mais aprofundado acerca da relação público/privado na oferta de vagas, quantidade de ingressantes, concluintes, número de polos e distribuição geográfica dos mesmos, a fim de contribuir para o aperfeiçoamento dos cursos, e consequentemente para a formação dos professores de EF.

Nesse sentido, destacamos que a grande maioria dos cursos é ofertada pelas IES vinculadas ao Sistema UAB, porém a quantidade de polos e de matrículas é quase equivalente entre as IES públicas e gratuitas vinculadas ao Sistema UAB, e as outras IES, dentre públicas municipais e comunitárias pagas e privadas. Este dado indica a necessidade de uma avaliação rigorosa a respeito do processo de gestão destas outras IES, tendo em vista que apenas um centro universitário

10-Indicador prévio da situação dos cursos de graduação no país.

Pensar a Prática, Goiânia, v. 16, n. 4, p. 956-1270, out./dez. 2013 
tem sob sua tutela 64 polos de apoio presencial com a oferta dos cursos de licenciatura e bacharelado, bem como do processo de ensino e aprendizagem, uma vez que não tivemos acesso aos projetos pedagógicos dos cursos destas quatro instituições. Este cenário é analisado por autores como Barreto (2008), Giolo (2008) e, Sousa (2007) como indício da precarização do ensino superior e do trabalho docente devido o barateamento da formação a partir dos modelos de educação adotados para abranger uma maior quantidade de alunos.

Outra preocupação que acaba sendo decorrente é em relação ao acompanhamento, supervisão e avaliação dos cursos, sejam eles públicos ou privados, tendo em vista o cuidado necessário com a qualidade do processo de ensino e aprendizagem que envolve a equipe gestora, os professores, tutores, infraestrutura física e material presente nos polos de apoio presencial, dentre outras características.

Ainda outro ponto derivado de uma análise mais ampliada diz respeito à continuidade de oferta pelas IES que já oferecem o curso. De acordo com os dados, apenas a UnB parece ter preocupação e interesse na oferta contínua dos cursos de licenciatura em EF, pois as demais IES vinculadas ao Sistema UAB participam apenas de um edital ou acabaram de começar o curso e não há dados que aponte, o interesse na continuidade.

Entre as quatro outras IES, três oferecem somente um curso em um único polo, e outra - que parece estar mais envolvida na expansão dos cursos de EF, tendo em vista que iniciou o curso de licenciatura em 2009 com a oferta de 2.000 vagas em 34 polos e em 2012 iniciou o curso de bacharelado com a oferta de 900 vagas em 30 polos.

Assim, percebe-se a partir dos dados coletados que há um grande número de cursos de EF sendo ofertados na modalidade de ensino a distância, o que confirma o processo de alteração nas formas de organização e expansão do ensino superior, marcado pelas mudanças no cenário sociopolítico e macroeconômico, e as orientações internacionais para as políticas educacionais no país a partir da década de 1990 .

EXPANSION OF HIGHER EDUCATION AND TRAINING IN PHYSICAL EDUCATION: A MAPPING OF COURSES IN DISTANCE EDUCATION MODE

\section{Abstract}

This article is an exploratory study that proposes a mapping offering Physical Education courses through Distance Education, seeking to identify the trends and nu- 
ances of this type of training as a strategy for expansion of higher education. The results mapped were (28) Physical Education courses at a distance, (24) by public institutions through the System UAB, and (4) by others institutions. However the number of places offered by others institutions is nearly $50 \%$ of enrollments. Understand that there is need for detailed studies on the process of teaching and learning in this mode, which requires studies about the topic of training the distance on the research agenda in the area.

Keywords: Physical Education and Training. Distance Education. Higher Education Policy.

\section{EXPANSIÓN DE LA EDUCACIÓN SUPERIOR Y FORMACIÓN EN EDU- CACIÓN FÍSICA: UN MAPEO DE CURSOS A DISTANCIA EN MODO DE EDUCACIÓN}

\section{Resumen}

Este artículo se trata de un estudio exploratorio lo cual propone una búsqueda de la oferta de cursos de Educación Física a través de la educación a distancia, tratando de identificar las tendencias y matices de este tipo de formación como estrategia para la expansión de la educación superior. Como resultados fueron asignados (28) cursos de Educación Física a distancia, siendo (24) por las instituciones públicas a través del sistema UAB y (4) cursos por otras instituciones. Sin embargo, el número de plazas ofertadas por las instituciones privadas es casi el $50 \%$ del total de las inscripciones. Entendemos que hay necesidad de realizar estudios detallados sobre el proceso de enseñanza-aprendizaje en esta modalidad, lo que requiere que el tema de la formación a distancia esté en la agenda de investigación en el área.

Palabras clave: Educación Física y Entrenamiento. Educación a Distancia. Política de Educación Superior.

\section{Referências}

BARRETO, R. G. As tecnologias na política nacional de formação de professores a distância - Entre a expansão e a redução. Educação e Sociedade. Campinas, v. 29, n. 104, p. 919-937, out., 2008. Especial.

BRASIL. Lei no 9394/96, de 20 de dezembro de 1996. Lei de Diretrizes e Bases da Educação Nacional. Diário Oficial [da] República Federativa do Brasil, Poder Legislativo, Brasília, DF, 23 dez. 1996. Seção 1, p. 27833.

BELLONI, M. L. Educação à distância. 3. ed. Campinas, SP: Autores associados, 2002.

DOURADO, L. F. Política e gestão da educação a distância: Novos marcos regulatórios? Educação e Sociedade. Campinas, v. 29, n. 104, p. 891-917, out., 2008. Especial. 
MINISTÉRIO DA EDUCAÇÃO (MEC). E-MEC: Instituições de educação superior e cursos cadastrados. Disponível em: http://emec.mec.gov.br/. Acesso em: 29 jan. 2013.

GIOLO, J. A educação a distância e a formação de professores. Educação e Sociedade. Campinas, v. 29, n. 105, p. 1211-1234, set./dez., 2008.

. Educação a distância: Tensões entre o público e o privado. Educação e Sociedade, Campinas, v. 31, n. 113, p. 1271-1298, out./dez., 2010.

INSTITUO NACIONAL DE ESTUDOS E PESQUISAS EDUCACIONAIS ANÍSIO TEIXEIRA (INEP). Censo da Educação Superior 2011. Disponível em: http://portal.inep.gov.br/web/censo-da-educacao-superior. Acesso em: 01 nov. 2012.

SELWYN, N. O uso das TIC na educação e a promoção de inclusão social: Uma perspectiva crítica do Reino Unido. Educação e Sociedade, Campinas, v. 29, n. 104, p. 815-850, out., 2008. Especial.

SOUSA, H. C. L. A (nova) política de formação de professores: A prioridade postergada. Educação e Sociedade. Campinas, v. 28, n. 100, p. 1203-1230, out., 2007. Especial.

TRIVIÑOS, A. N. S. Introdução à pesquisa em ciências sociais: a pesquisa qualitativa em educação. São Paulo: Atlas, 1994.

UNIVERSIDADE ABERTA DO BRASIL (UAB). Disponível em: http://www.uab.capes.gov.br/index.php. Acesso em: 01 nov. 2012.

UNIVERSIDADE FEDERAL DE GOIÁS (UFG). Faculdade de Educação Física. Formação em rede: apresentação. Disponível em: http://www.fer.fef.ufg.br/. Acesso em: 25 jan. 2013.

Recebido em: 17/08/2013

Revisado em: 04/11/2013

Aprovado em: 13/11/2013

Endereço para correspondência

arilazzarotti@gmail.com

Ari Lazzarotti Filho

Pensar a Prática, Goiânia, v. 16, n. 4, p. 956-1270, out./dez. 2013 
DOI: 10.5216/rpp.v16i4.26072 